\title{
GESTÃO DO TRABALHO E DA EDUCAÇÃO NA SAÚDE (GTES): NOVAS PROPOSTAS, ANTIGAS IDEIAS
}

Luciano Silveira Pacheco de Medeiros Mestrando em Saúde Coletiva, Universidade do Extremo Sul Catarinense, saude.educacao@jaraguadosul.sc.gov.br

Helen Bruggemann Bunn Schmitt Mestra, Universidade Federal de Santa Catarina, diretoriasaude11@gmail.com Marco Antônio de Medeiros

Licenciado em Filosofia, Pontifícia Universidade Católica do Rio Grande do Sul, marcosantti@gmail.com Rosana Mara da Silva Mestranda em Gestão de Políticas Públicas, Universidade do Vale do Itajaí, rosanacrestani@terra.com.br Luciane Bisognin Ceretta Doutora, Universidade do Extremo Sul Catarinense, luk@unesc.net Rita de Cassia Veiga Enfermeira, Instituto de Ensino e Pesquisa - Hospital Sírio Libanês, ritadecassiaveiga@hotmail.com

\section{RESUMO}

O estudo teve como objetivo apurar o conhecimento dos gestores da Secretaria Municipal da Saúde de Jaraguá do Sul (SEMSA), em Santa Catarina 
(SC), acerca das competências/atribuições do Setor de Gestão do Trabalho e da Educação na Saúde (GTES), além de todas as articulações necessárias para que a política instituída pelo Ministério da Saúde (MS) alcance os impactos objetivados na prática diária dos profissionais da área da saúde e na sistematização dos processos de trabalho, na consequente melhoria da assistência aos usuários e dos cenários de prática, bem como as singularidades envolvidas no processo de criação/efetivação e operacionalização deste importante dispositivo de controle social. O trabalho de estruturação de um setor é permeado de singularidades que nem sempre são percebidas com entendimento e clareza suficientes por quem se encontra na posição de expectador, e algumas de suas nuances podem passar despercebidas, principalmente no que se refere às competências e aos valores agregados a ele. Está previsto no Plano Municipal de Saúde 2014-2017 a criação/ efetivação do GTES para o ano de 2014, porém se observou que, em virtude de vontade política local, essa meta não foi cumprida, pelo menos até o final de 2015, o que, de maneira geral, deixou o GTES responsável por momentos pontuais de capacitaçóes, o que nos reporta à velha prática de educação continuada. A pesquisa é descritiva, com análise interpretativa e abordagem quali-quantitativa. A amostra foi não aleatória, composta por 20 gestores da SEMSA. Os dados foram coletados por meio da aplicação de entrevistas semiestruturadas (cinco questóes abertas e sete questóes fechadas), durante os meses de fevereiro a março de 2015. Após a etapa da coleta, compilação e análise dos dados, foi construído o Discurso do Sujeito Coletivo (DSC), de Lefèvre e Lefèvre. Quanto às ferramentas disponíveis e aplicáveis às pesquisas de caráter quali-quantitativo, usou-se, para o delineamento do trabalho: Mapa de Alta Direção de Planejamento Popular (MAPP), na etapa da construção do pressuposto norteador pelo pesquisador, e Arco de Marguerez, como ferramenta de apoio. O DSC demonstrou uma fala fragmentada, podendo afirmar que o nosso "gestor" conhece parcialmente as competências e atribuiçóes do GTES, porém demonstra desconhecimento acerca da Política Nacional de Educação Permanente em Saúde (PNPES). Em encontro acontecido no mês de junho de 2015, trabalharam-se dinâmicas que auxiliaram na explanação das competências/atribuições do GTES, à luz da PNPES e diretrizes norteadoras do MS; a reestruturação/organização dos fluxos do GTES; 
apresentação das duas primeiras propostas de portarias relacionadas ao GTES, sendo a primeira para criar e formalizar o setor, enquanto a segunda para instituir normativa para regulamentar a liberaçáo, a pedido, aos eventos de qualificação profissional dos servidores lotados na SEMSA; apresentação da Plataforma de Educação a Distância (EaD) para cursos de capacitação/atualização dos servidores lotados na SEMSA. Por meio do DSC, nosso "gestor" conhece parcialmente as competências/atribuiçóes do GTES. A segmentação desses saberes tornouse evidente quando sua fala ficou centrada apenas no campo da Educação em Saúde. Em raros momentos, nosso "gestor" fez alusão à Gestão do Trabalho e, quando a fez, mencionou brevemente por meio da seguinte afirmativa: "[...] desenvolvimento das competências dos servidores, tendo como 'produto final' a melhoria dos processos de trabalhos, refletindo no atendimento ao usuário", o que foi aprovado em novembro de 2013, contemplando a criação e a efetivação do GTES já para o ano de 2014, pois, neste documento, quando analisado, não encontramos contempladas, em momento algum, ação do GTES no campo da Gestão do Trabalho, mas somente no campo da Educação na Saúde, e o que piorou a situação foi uma terrível confusão de leituras e significações entre Educação Popular e Educação Permanente em Saúde (EPS). Após a coleta, compilação, análise dos dados e construção do DSC, percebeu-se que os gestores da SEMSA desconhecem a Política Nacional de Educação Popular em Saúde (PNEPS) e boa parte das diretrizes propostas para o GTES, bem como as competências/ atribuiçóes do referido setor, quase que na sua totalidade, mesmo tendo sido proposto quando da elaboração do Plano Municipal da Saúde. Percebeu-se que essa incongruência entre proposição/ação data das propostas aprovadas na $5^{\text {a }}$ Conferência Municipal de Saúde, já que os planos municipais de saúde nasceram das propostas aprovadas nessas plenárias. Contudo, a gênese da questão é o desconhecimento dos atores sociais envolvidos no estudo, acerca de determinadas políticas públicas de saúde, neste caso a PNEPS. Sabemos que mudanças são provocativas e desconfortáveis, causando estranhezas e inquietações, porém necessárias para a vida útil de todas as instituições, não diferindo no serviço público. Quando propomos “criar”, desejamos, a priori, transformar uma situação que nos incomoda e que necessitamos mudá-la, todavia devemos nos apoderar 
das ferramentas necessárias, a fim de que tais mudanças sejam reais e produzam efeitos positivos nos cenários que desejamos alterar.

Palavras-chave: Gestão do Trabalho e da Educação na Saúde; Gestor; Políticas de Educação Permanente; Educação em Saúde.

\section{REFERÊNCIAS}

BRASIL. Ministério da Saúde. Portaria GM/MS no 1996, de 20 de agosto de 2007, Diretrizes para a Implementaçáo da Política Nacional de Educaçáo Permanente em Saúde. Brasília: Diário Oficial da União, 2007.

. Conselho Nacional de Saúde. Princípios e diretrizes para gestáo do trabalho no SUS. Brasília: Ministério da Saúde, 2005.

. Conselho Nacional de Saúde. Resoluçóes do Conselho Nacional de Saúde. Brasília: Ministério da Saúde, 2007.

. Secretaria de Gestão do Trabalho e da Educação na Saúde. Política de desenvolvimento para o SUS: caminhos para a educação permanente em saúde: polos de educação permanente em saúde. Brasília: Ministério da Saúde, 2004.

JARAGUÁ DO SUL. Secretaria Municipal de Saúde. Plano Municipal de Saúde 2014-2017. Jaraguá do Sul: Semsa, 2014.

LEFÈVRE, F.; LEFÈVRE, A. M. C. O discurso do sujeito coletivo: um enfoque em pesquisa qualitativa. 2. ed. Caxias do Sul: Educs, 2005. 